\title{
A study of the symptoms of gastro-esophageal reflux disease and associated risk factors among the rural school children of Veleru India
}

Gunda Jahnavi, Satya Ranjan Patra', Sarah E. Singh ${ }^{2}$

Departments of Community Medicine, and ${ }^{1}$ Surgery, Madha Medical College and Research Institute, Kovur, Thandalam, Chennai, Tamil Nadu, India,

${ }^{2} \mathrm{BA}$ (Biological Scienes) Binghamton University, 4400 Vestal Parkway

East, Vestal, NY 13850, USA

Address for the Correspondence:

Dr. G. Jahnavi,

Department of Community Medicine, Madha Medical College, Kovur, Thandalam, Chennai - 600122

Tamil Nadu, India.

E-mail: jahnavi_doc@yahoo.com

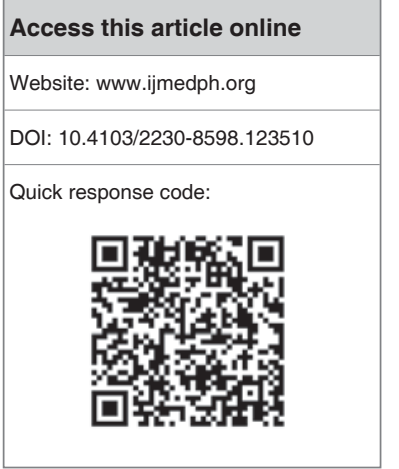

Background: Prevalence of gastro-esophageal reflux disease (GERD) in all ages has shown an upward trend over the past decades. The reasons for this increase are ill-understood. The data in the pediatric population is limited. Recent studies have linked childhood GERD to adult GERD. This study was conducted to assess the symptoms, risk factors of GERD among the schoolchildren residing in a rural area. Aims: The aim of this study was to find out the prevalence of GERD risk factors among the school children aged 8-17 years and to find any association between body mass indexes, meal pattern and sleep disturbances related to GERD. Materials and Methods: We did a cross-sectional study on 380 school children of $4^{\text {th }}-10^{\text {th }}$ standard from 4 schools of Veleru, the Rural Health Center attached to Dr. Pinnamaneni Siddhartha Institute of Medical Sciences. The questionnaire consisted of questions for reflux symptoms, meal pattern and sleep disturbances. Results: The symptoms of reflux like abdominal pain was reported in $7 \%$, heartburn in $1.3 \%$, regurgitation in $2.4 \%$, vomiting in $2.9 \%$, difficulty in swallowing in $2.1 \%$, sore taste in mouth in $0.8 \%$ of the children. The risk-factors for reflux like caffeinated drinks were found in $45.3 \%$, very spicy food in $12.1 \%$, heavy meals in $2.4 \%$ of the children. Sleep disturbance was seen in $33.4 \%$ of the children. Obesity was present in $0.6 \%$ of the children. Conclusion: School children should be informed about the symptoms and risk factors of GERD so that healthy dietary habits can be developed at a young age and GERD can be prevented.

Key words: Dietary habits, gastro-esophageal reflux disease, school children

\section{INTRODUCTION}

The chronic symptoms of gastro-esophageal reflux disease (GERD) are due to mucosal damage caused by stomach acid coming up from the stomach into the esophagus. GERD is usually caused by changes in the barrier between the stomach and the esophagus, including abnormal relaxation of the lower esophageal sphincter which normally holds the top of the stomach closed; impaired expulsion of gastric reflux from the esophagus or a hiatal hernia. These changes may be permanent or temporary.

Every year GERD affects approximately 4.5/1000 persons in the United Kingdom ${ }^{[1]}$ and 5.4/1000 persons in the United States. ${ }^{[2]}$ In Western populations, the prevalence of GERD ranges from $10 \%$ to $20 \%$. GERD symptoms occur at least once a month in $44 \%$, once a week in $20 \%$ and daily in $7 \%$ of the adult US population. ${ }^{[3-5]}$ However, studies describing the epidemiology of GERD in South-East Asia and for that matter in India are sparse; and traditionally GERD was thought to be uncommon in the developing countries, ${ }^{[6]}$ on the other hand, studies in the multiethnic population showed that people of Indian origin are at higher risk of GERD than ethnic Malay and Chinese. ${ }^{[7]}$ And the studies done in India emphasize that the prevalence of GERD in India is likely to be between $8 \%$ and 19\%, which is comparable with GERD prevalence rates published in western countries. In addition, these studies highlight that the risk factors for GERD are related to diet and life-style preferences, which are both modifiable risk factors.

A study by Bhatia et al..$^{[8]}$ in a multi-center prospective questionnaire-based study of 3,224 urban and rural patients and reported a weekly prevalence of $7.6 \%$ in the Indian population. There are other questionnaire 
based cross-sectional studies by Sharma et al. and Kumar et al., [9,10] which also showed a high weekly prevalence of GERD (16.2-18.7\%).

Contrary to the previous held belief, prevalence of GERD in India is in fact much higher and similar to that reported in the western world. However, it is unclear if this represents a true increase in the prevalence of the disease or the reporting has increased due to heightened awareness of acid reflux. In recent years, the progress in the Indian society on both socio-economic and educational fronts has led to changes in diet and life-style choices. This advancement has also resulted in adaptation of Western diet and life-style such as consuming fried and sweet foods, processed and red meat, refined grains and high-fat dairy products, carbonated drinks, which in turn led to increase in prevalence of GERD.

Childhood GERD is a risk factor for GERD in adolescence and adulthood. ${ }^{[11]}$ The symptoms of GERD in children are chest pain, refusal to eat, dysphagia, frequent sore throat, respiratory problems such as wheezing, bronchitis and asthma, frequent cough, poor sleep and frequent waking, excessive salivation. ${ }^{[12]}$

A study by Lagergren et al., showed that GERD symptoms precede the diagnosis of cancer in about $60 \%$ of patients with esophageal adenocarcinoma. In the same study, the odds ratio for esophageal adenocarcinoma was 43.5 in individuals with long-standing and severe symptoms of reflux. ${ }^{[13]}$ As there has been a dramatic increase in the incidence of carcinoma of the distal esophagus in the western world; ${ }^{[14,15]}$ hence, there is an urgent need for early recognition and treatment of GERD and the diseases associated with it, not only in the west, but in India as well.

\section{MATERIALS AND METHODS}

We did a cross-sectional study on 380 school children of $4^{\text {th }}-10^{\text {th }}$ standard from four different schools of Veleru the Rural Health Center attached to Dr. Pinnamaneni Siddartha Institute of Medical Sciences. The study was conducted from November 2010 to January 2011. The students who were present on the days of a visit to that particular school were included in the study. The questionnaire consisted of questions for reflux symptoms, meal pattern and sleep disturbances. The purpose of the study was explained to the students present in the class at the time of the survey. The questionnaires were administered to them and were requested to answer the questions. The stature and body weight were measured with an anthropometric rod and a properly calibrated weighing machine respectively to calculate body mass index (BMI). Children with BMI $\geq 30 \mathrm{~kg} / \mathrm{m}^{2}$ were regarded as obese, 25.0-29.9 as overweight and with BMI 18.5-24.9 as normal. After completion, an awareness program was conducted in the school for teachers and the students regarding GERD and during the interactive session all their doubts also were cleared.

\section{RESULTS}

A total of 380 school children belonging to the rural area were interviewed in the study. After the interview, we explained to the children as to how GERD occurs and how it could be prevented. Their doubts regarding GERD were cleared.

Basic characteristics of the school children are depicted in Table 1. The mean age group of the school children studies was 13.5 years. The boys constituted $61.6 \%$ of the study population. Only two children were found to be overweight.

Morbidity profile of the school children is depicted in Table 2. A total of $111(29.2 \%)$ of the children were suffering from one or the other illness during the past 2 weeks. $46(12.1 \%)$ of the children were suffering from viral illness followed by $44(11.6 \%)$ of children from cough, 14 (3.7\%) from fever, 4 (1.1\%) from diarrhea and $3(0.8 \%)$ from shortness of breath.

School children having the symptoms of GERD are shown in Table 3. A total of $65(17.3 \%)$ of the children were having one or the other symptoms of GERD in the past 1 week, of which 26 (6.9\%) children complained of upper abdominal pain, 11 (2.9\%) children complained of vomiting, 9 $(2.4 \%)$ from nausea, $8(2.1 \%)$ from pain while swallowing food or drink, $5(1.4 \%)$ from chest pain, $3(0.8 \%)$ from sour taste in the mouth, $3(0.8 \%)$ children complained of waking up at night due to heart burn.

\begin{tabular}{lc} 
Table 1: Physical attributes of the school children \\
\hline Basic characteristics & School children, $\boldsymbol{n = 3 8 0}(\%)$ \\
\hline Age in years & $13.5 \pm 2$ \\
Boys & $234(61.6)$ \\
Girls & $146(38.4)$ \\
Body mass index $\left(\mathrm{kg} / \mathrm{m}^{2}\right)$ & \\
Underweight $(<18.5)$ & $212(55.8)$ \\
Normal $(18.5-24.99)$ & $166(43.7)$ \\
Overweight $(\geq 25)$ & $2(0.5)$ \\
\hline
\end{tabular}

\begin{tabular}{lc}
\hline Table 2: Distribution of school children according \\
to different morbid conditions in the past $\mathbf{2}$ weeks \\
\hline Morbidity & School children, $\boldsymbol{N}$ (\%) \\
\hline Viral illness & $46(12.1)$ \\
Cough & $44(11.6)$ \\
Fever & $14(3.7)$ \\
Diarrhea & $4(1.1)$ \\
Shortness of breath & $3(0.8)$ \\
Total & $111(29.2)$ \\
\hline
\end{tabular}

\begin{tabular}{lc} 
Table 3: Symptoms of GERD during the past 1 week \\
\hline Symptoms of GERD & School children, $\boldsymbol{N}(\%)$ \\
\hline Abdominal pain (upper) & $26(6.9)$ \\
Vomiting & $11(2.9)$ \\
Nausea & $9(2.4)$ \\
Pain while swallowing & $8(2.1)$ \\
Chest pain & $5(1.4)$ \\
Sour taste in the mouth & $3(0.8)$ \\
Waking up at night due to heart burn & $3(0.8)$ \\
Total & $65(17.3)$ \\
\hline
\end{tabular}

GERD = Gastro-esophageal reflux disease 
Dietary and life-style parameters of the school children are depicted in Table 4. The school children were asked about the frequency of consumption of aerated drinks. For all dietary items and medication the frequency was categorized as never, 1-3 times/week as infrequent and $>3$ times/week as frequent. More than half of the children were consuming aerated drinks out of which 60 (15.8\%) children were taking frequently. The school children were asked about their coffee/ tea intake per day, 193 children (50.8\%) were consuming 1-3 cups/day. The children were asked about their dinner intake; they were asked to classify the amount of intake on a subjective basis as heavy, moderate and light. When the child felt stuffed and uncomfortable after eating it was considered as heavy meal; when he felt comfortably full after dinner, it was considered as moderate; when he did not feel full after dinner then it was considered as light. Heavy meals were taken by $9(2.4 \%)$ of the children. The children were asked about whether they took spices in their diet; they were asked to classify the intensity of spicy diet on a subjective basis as very spicy, some, little and none. Very spicy food was consumed by 46 (12.1\%) of the children.

Figure 1 depicts the number of children on medication during the last 1 week. Out of 26 children who were having abdominal pain, $20(76.9 \%)$ were on painkillers and $6(23 \%)$ were on antacids.

Table 5 depicts the correlation between the life-style parameters and the GERD symptoms. It was observed that there is a significant association between ingestion of coffee/tea, spicy food intake, ingestion of aerated drinks and GERD symptoms.

\section{DISCUSSION}

The commonly prevalent diseases amongst rural Indian children are diarrhea, respiratory tract infections and worm infestation. With the spread of means of mass communication like television, children of the rural area too have started consuming fast food, aerated drinks etc. These life-style changes may subtly contribute to the burden of GERD. As the evidence is increasing that GERD has origin in childhood, it is necessary to find out the problem of GERD as well as spread awareness so that early detection and treatment of GERD in children may result in a better long-term outcome, improved quality-of-life and a reduction in overall health-care burden.

The prevalence of GERD in the rural school children marks the first step in understanding the disease in this age group. Despite the various studies on GERD, there are several gaps in the knowledge regarding the children of this age. It is a well-documented disease in infants and the affluent middle aged, but has nothing to do with this specific age group only. The symptomatology of GERD is very non-specific and most patients are treated for respiratory tract diseases unnecessarily.

The present study was conducted as a part of the GERD awareness week from November $18^{\text {th }}$ to $24^{\text {th }}$ by the international foundation for functional gastrointestinal (GI) disorders. It was conducted in the rural area in apparently healthy school children and showed that $65(17.3 \%)$ of the children had GERD symptoms. Although other associating factors such as BMI, ingestion of heavy meals could not be proved, the association between tea/coffee, aerated drinks and spicy food has been found to be significant.

A few studies have implicated foods that may precipitate reflux symptoms including dietary fat, chocolates, coffee, onions, citrus fruits, tomatoes and mints; it has been postulated that these foods mediate their effects through relaxation of the lower esophageal sphincter. In our study, we found that coffee, tea, aerated drinks and spicy food has been associated with the reflux symptoms.

Further, this is one disease, which can be prevented by very simple modifications to one's life-style. Life-style modifications include

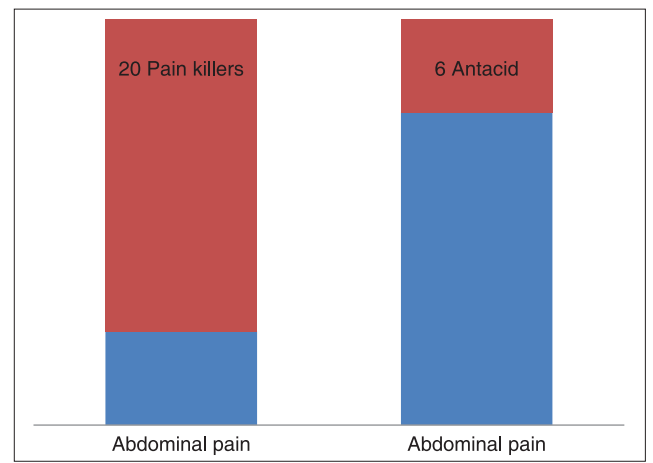

Figure 1: The number of children with abdominal pain on medication during last 1 week

\begin{tabular}{|c|c|}
\hline Dietary and life-style parameters & School children, $N(\%)$ \\
\hline \multicolumn{2}{|l|}{ Ingestion of aerated drinks } \\
\hline Infrequent (1-3 times/week) & $21(5.5)$ \\
\hline Frequent (>3 times/week) & $60(15.8)$ \\
\hline \multicolumn{2}{|l|}{ Ingestion of tea/coffee } \\
\hline $1-3$ cups/day & $193(50.8)$ \\
\hline$>3$ cups/day & $1(0.3)$ \\
\hline \multicolumn{2}{|l|}{ Dinner intake } \\
\hline Heavy & $9(2.4)$ \\
\hline Moderate & $218(57.4)$ \\
\hline Light & $153(40.2)$ \\
\hline \multicolumn{2}{|l|}{ Spices in the food } \\
\hline Very spicy & $46(12.1)$ \\
\hline Some & $183(48.2)$ \\
\hline Little & $148(38.9)$ \\
\hline None & $3(0.8)$ \\
\hline
\end{tabular}

\begin{tabular}{|c|c|c|}
\hline $\begin{array}{l}\text { Dietary and life-style } \\
\text { parameters }\end{array}$ & GERD symptoms & $\chi^{2}$ test \\
\hline Ingestion of tea/coffee & $53 / 194$ & $p<0.001$ \\
\hline $\begin{array}{l}\text { Spicy food } \\
\text { (very and some) }\end{array}$ & $60 / 229$ & $p<0.001$ \\
\hline Aerated drinks & $47 / 60$ & $p<0.001$ \\
\hline
\end{tabular}

GERD = Gastro-esophageal reflux disease 
avoidance of foods and dietary items known to exacerbate reflux. Some of these incriminating foods include tomatoes, citrus products, fried/fatty/spicy foods, carbonated beverages, chocolates and even dairy products. Obesity and late night snacks can aggravate gastroesophageal reflux symptoms. Avoidance of the supine position on a full stomach and minimizing increased intra-abdominal pressure such as occurs during certain activities and sports may be worthwhile.

Confirmation studies for GERD like $\mathrm{pH}$ monitoring examination or esophageal manometry are available only in select centers. Most cases are misdiagnosed and due to non-specific symptoms of the disease. Health professionals of our country are unaware about the true incidence of the disease and tend to overlook it in the differential diagnosis.

Most cases are identified by upper GI endoscopy when clear-cut hiatus hernia is present or when metaplasia has occurred. The incidence of gastro-esophageal junction carcinoma is increasing in our country. Early suspicion and management of the condition would be helpful by simple measures like eating small and frequent meals and to avoid lying down $3 \mathrm{~h}$ after a meal; might help this group of patients.

\section{CONCLUSION}

Childhood GERD is a frequently overlooked disease. Incidence of childhood GERD should be found out by conducting more studies in India. Children should be made aware of the precipitating and relieving factors to prevent long-term complications such as metaplasia and adenocarcinomas.

\section{Recommendation}

If the children are made aware about GERD then they will help spread the message in their peer group; this might help prevent non-steroidal anti-inflammatory drugs abuse/over use.

\section{REFERENCES}

1. Dent J, El-Serag HB, Wallander MA, Johansson S. Epidemiology of gastro-oesophageal reflux disease: A systematic review. Int J Gastroenterol Hepatol 2005;54:710-7.

2. DeVault KR, Castell DO. Updated guidelines for the diagnosis and treatment of gastroesophageal reflux disease. The practice parameters committee of the American College of Gastroenterology. Am J Gastroenterol 1999;94:1434-42.

3. Nebel OT, Fornes MF, Castell DO. Symptomatic gastroesophageal reflux: Incidence and precipitating factors. Am J Dig Dis 1976;21:953-6.

4. A Gallup Organization National Survey: Heartburn Across America. Princeton: The Gallup Organization; 1988.

5. Locke GR $3^{\text {rd }}$, Talley NJ, Fett SL, Zinsmeister AR, Melton LJ $3^{\text {rd }}$. Prevalence and clinical spectrum of gastroesophageal reflux: A population-based study in Olmsted County, Minnesota. Gastroenterology 1997;112:1448-56.

6. Sharma P, Wani S, Romero Y, Johnson D, Hamilton F. Racial and geographic issues in gastroesophageal reflux disease. Am J Gastroenterol 2008;103:2669-80.

7. Ho KY, Kang JY, Seow A. Prevalence of gastrointestinal symptoms in a multiracial Asian population, with particular reference to reflux-type symptoms. Am J Gastroenterol 1998;93:1816-22.

8. Bhatia SJ, Reddy DN, Ghoshal UC, Jayanthi V, Abraham P, Choudhuri G, et al. Epidemiology and symptom profile of gastroesophageal reflux in the Indian population: Report of the Indian society of gastroenterology task force. Indian J Gastroenterol 2011;30:118-27.

9. Sharma PK, Ahuja V, Madan K, Gupta S, Raizada A, Sharma MP. Prevalence, severity, and risk factors of symptomatic gastroesophageal reflux disease among employees of a large hospital in Northern India. Indian J Gastroenterol 2011;30:128-34.

10. Kumar S, Sharma S, Norboo T, Dolma D, Norboo A, Stobdan T, et al. Population based study to assess prevalence and risk factors of gastroesophageal reflux disease in a high altitude area. Indian $\mathrm{J}$ Gastroenterol 2011;30:135-43.

11. El-Serag HB, Gilger M, Carter J, Genta RM, Rabeneck L. Childhood GERD is a risk factor for GERD in adolescents and young adults. Am J Gastroenterol 2004;99:806-12.

12. Gremse DA. GERD in the pediatric patient: Management considerations. MedGenMed 2004;6:13.

13. Lagergren J, Bergström R, Lindgren A, Nyrén O. Symptomatic gastroesophageal reflux as a risk factor for esophageal adenocarcinoma. N Engl J Med 1999;340:825-31.

14. Devesa SS, Blot WJ, Fraumeni JF Jr. Changing patterns in the incidence of esophageal and gastric carcinoma in the United States. Cancer 1998;83:2049-53.

15. Pera M, Cameron AJ, Trastek VF, Carpenter HA, Zinsmeister AR. Increasing incidence of adenocarcinoma of the esophagus and esophagogastric junction. Gastroenterology 1993;104:510-3.

How to cite this article: Jahnavi G, Patra SR, Singh SE. A study of the symptoms of gastro-esophageal reflux disease and associated risk factors among the rural school children of Veleru India. Int J Med Public Health 2013;3:321-4.

Source of Support: Nil, Conflict of Interest: None declared. 